The Bright Side of the Economic Crisis:

The Attribution of Political Responsibilities in Hard Times

Guillermo Cordero and Ignacio Lago

\title{
IMPORTANT NOTICE:
}

Following the instructions of the "Terms and Conditions for authors to Canadian Journal of Political Science/Revue canadienne de science politique", we warn that this is an Accepted Manuscript (AM) version of the article. This article has been accepted for publication and appears in a revised form, subsequent to peer review and editorial input by Cambridge University Press, in Canadian Journal of Political Science/Revue canadienne de science politique published by Cambridge University Press.

\section{Details of the publication:}

Cordero, G. and Lago, I. 2016. "The Bright Side of the Economic Crisis: The Attribution of Political Responsibilities in Hard Times". Canadian Journal of Political Science. doi: 10.1017/S0008423916000044. [Link to the Cambridge website address for the Article] 
The Bright Side of the Economic Crisis:

The Attribution of Political Responsibilities in Hard Times

Abstract: We examine the impact of the current economic crisis on the accuracy of responsibility attribution between levels of government within States. Using individuallevel data from Spain, we show that learning about responsibility attribution depends on the saliency of the issue (in our study, unemployment) and economic self-interest. The (unintended) positive consequence of economic crisis is that citizens are now more able to accurately attribute the responsibility for political decisions than some years ago. Learning is particularly significant among those individuals more affected by the economic crisis.

KEYWORDS:

ATTRIBUTION OF RESPONSIBILITY - ECONOMIC CRISIS DECENTRALIZATION - MULTILEVEL GOVERNMENT 


\section{INTRODUCTION}

One of the best-established propositions in the literature about representation in contemporary democracies is that 'accountability, if it is to be properly exercised, first requires citizens to make attributions of responsibility' (Rudolph, 2003b: 700). With the intensifying global trend towards decentralization over recent decades ${ }^{\mathrm{i}}$, increasing attention has been devoted to how voters attribute responsibilities between levels of government within States.

Roughly speaking, there have been two main research questions on the attribution of political responsibilities: to what extent multilevel governance undermines clarity of responsibilities and hence affects economic voting (for instance, C.A. Anderson, 2006; Cutler, 2004; Hobolt and Tilley, 2014; or León, 2010), and more recently, under which circumstances citizens are more likely to learn about responsibility attribution over time (León, 2012). We focus in this paper on learning as the scant existing research is, in our view, subject to several substantive and methodological shortcomings. The lack of a model of learning grounded in social psychology and cognitive science does not allow us to account for differences in learning across policy areas and individuals: not all individuals learn in the same way about the same things.

Multilevel governance improves the quality of public policy and reduces the administrative costs by increasing the proximity between government and citizen as well as governmental understanding of citizen preferences (see Escobar-Lemmon, 2003 or Weingast, 1995). However, if the electoral control of incumbents falters as a result of an inability to assign responsibility in multilevel governance, then incumbents do not really fear losing the next election and then they will not be representative (C.A. Anderson, 
2006). Given this potential trade-off between efficiency and accountability in multilevel governance in the short term, the long-term outputs of decentralization crucially depend on learning. If citizens are able to learn about political responsibilities, then the trade-off is ameliorated as time goes by.

We argue that the accuracy of individuals' attribution of responsibilities depends on the attention they pay to political issues, particularly those individuals who derive benefits from having information about specific policy areas. Apart from group-serving biases and institutional designs, we show that there is a third variable affecting responsibility attribution: the saliency of issues at a specific point in time. That is, differences in the attribution of responsibilities can be found not only across individuals and institutional settings, but also over time.

We focus on Spain as an example of similarly decentralized democracies. Spain is a quasi-federal parliamentary democracy (Linz, 1989) in which the regional level of government holds significant competences in the welfare state, such as education and healthcare, while the central level maintains other competencies, such as the administration of justice, defence or immigration. The recent process of devolution resulted in a fragmentation of competences which has diffused the attribution of responsibility by citizens. The economic crisis in Spain, also provides an ideal scenario for testing our argument about learning as the saliency of policies has dramatically changed in only a few years. The spectacular increase in the unemployment rate, from 8.3 percent in 2007 to 25.0 percent in 2012, accompanied by the significant reduction in the importance of previously crucial issues, such as immigration or housing for instance, 
allows us to test whether the public interest in issues that arise and individuals' selfinterest drive the attribution of responsibility..

We rely on individual data from two surveys in late 2007 and 2012 to disentangle the mechanisms that account for learning about responsibility attribution in multilevel government systems. Our results show that the (unintended) positive consequence of the current economic crisis and the enormous increase in unemployment rates is that citizens are now more able to accurately attribute the responsibility for political decisions in relation to this policy than some years ago. Learning is particularly significant among those most affected by the economic crisis - the working population. This is the bright side of the economic crisis.

The rest of the article is organized as follows: In the next section, the previous literature and our argument about citizens' learning about responsibility attribution are presented. The third section describes the data and methods. The fourth section discusses the results of the empirical analysis. Section five presents our conclusions and suggestions for further research.

\section{ARGUMENTS}

When explaining the outputs of institutions (i.e., how they affect the behaviour of political actors), learning is crucial. Institutions matter when the actions of citizens or elites are driven by the incentives provided by the rules of the game. Of course, a necessary condition for this effect of institutions is that actors are aware of those incentives. Therefore, the expected outputs of institutions are often not observed immediately, but in the medium- or the long-term, once actors have good information. 
For instance, the electoral-systems literature indicates that the strategic behaviour of parties and voters produces a long-term equilibrium relationship between the size of party systems at the electoral and legislative levels (Cox, 1997). Since actors' instrumental rationality is a standard concern, differences over time within countries in the level of coordination or the speed at which the equilibrium is reached are a function of the quality of the information about the electoral prospects of competitors. This is what Tavits and Annus (2006) define as the developmental argument of strategic voting (i.e., the strategic behaviour of voters increases with time as a result of a learning process).

The literature on attributing responsibility correctly in multilevel states has shown that citizens' perceptions of political responsibility are influenced by group-serving biases -partisanship- and the institutional context, particularly the division of responsibilities. Firstly, information about government responsibility is not randomly distributed among individuals. Individual-level differences are related to voters' economic ideologies and party identification (Rudolph, 2003a, 2003b). More recently, Tilley and Hobolt (2011), Hobolt et al. (2013) and Hobolt and Tilley (2014) have used the concept of group-serving biases to capture the individual predispositions shaping attributions of responsibilities: individuals tend to give credit to the groups they favour for positive outcomes and to blame rival groups or an exogenous constraint for negative outcomes (Hobolt et al., 2013: 154).

Secondly, institutional arrangements have a crucial role in shaping attributions of responsibility. As is well known in the literature about electoral accountability (see C.J. Anderson, 2007a, 2007b), the connection between a voter's perception of the economy and their vote depends on the extent to which structural features of polities can hinder 
voters' access to information about representatives' activities. The general argument, based above all on Powell and Whitten (1993), is that institutions increase or reduce citizens' capacity to reward or punish incumbents. Once voters have formed their opinion about the state of the economy, the transformation to a vote in favour or against the incumbent depends on (or interacts with) what they believe is the responsibility of the incumbent. Meanwhile, certain institutional measures result in a greater 'clarity of responsibility' of governments, expressed in the electoral results of the politicians who introduced these measures. And given the difficulty in deciding whom to reward or punish when this clarity does not exist, a voter's ability to rely on their own evaluation of economic results is undermined. Thus, the clearer the responsibility of the government for the results of its own policies, the more the economy affects the electoral support of incumbents. C.J. Anderson (2000: 168) summarized the evidence in the following way: “(...) these findings suggest that voters' ability to express discontent with economic performance is enhanced when accountability is simple. Voters' economic assessments have stronger effects on government support when it is clear who the target is, when the target is sizable, and when voters have only a limited number of viable alternatives to throw their support to". More recently, it has been shown that when there is a dispersion of political authority among multiple levels of government, the clarity of responsibility is diminished (C.A. Anderson, 2006 or Leon, 2010, 2012). When there is only one government (national), (almost) all the responsibility is in its hands. However, if there are also sub-national governments, the assignment of political responsibility is no longer direct: in this instance, voters need to know whether the competence in each matter is shared or exclusive. In two recent academic studies, Duch and Stevenson (2013) and Duch et al. (2014) show that individuals have general responsibility attribution heuristics 
that apply to collective decisions: individuals tend to assign responsibility to the decision maker with agenda power and with the largest vote share.

In Spain, a substantial body of literature in the last ten years has investigated the extent to which individuals are able to correctly assign political responsibilities to national and regional incumbents (Herrero et al, 2015; Lago and Lago, 2010, 2013; León, 2010, 2012, 2015; León and Ferrín, 2007; López Laborda and Rodrigo, 2012, 2014). Roughly speaking, the main findings are fourfold: (i) when asked about the level of government with the main responsibility over seven policies (unemployment insurance, healthcare, education, retirement and disability pensions, transports, and infrastructures), the average number of correct answers is three out of seven attributed responsibilities; (ii) unemployment insurance and pensions (that is, those exclusively in the hands of the national government) are the policies with the highest percentage of correct answers; (iii) there is some evidence of learning over time, particularly in the case of those individuals who are highly informed and interested in politics, and (iv) the relationship between decentralization and clarity of responsibility has a u-shape: responsibility attribution is clearer in regions with high and low levels of decentralization (i.e., where one level of government clearly predominates over the other) than in regions with a more intertwined distribution of powers.

However, when accounting for learning about responsibility attribution in multilevel structures, there is no a model explaining why some individuals, but not others, are able to learn who is responsible for what; or why individuals learn about some policies but not all of them. The (flawed) assumption is that learning is automatic and passive. This is particularly relevant when there is no common pattern of learning across policy areas 
depending on the level of government with the primary responsibility or the ideology of the incumbent, as in our case. The information hypothesis -which states that those actors who have greater access to information, who are more educated and who are more sophisticated, should make more accurate responsibility attributions- can hardly explain differences over time and across policy areas for the same individual. We need a theory to explain when people learn and which people learn.

According to the model on human decision making by Lupia and McCubbins (1998: chapter 2), human learning is not automatic, but active. The prerequisite for learning anything is paying attention; as learning requires effort and effort is a scarce resource for everyone, people choose what and when to learn. Additionally, the purpose of paying attention is to make reasoned choices (i.e., people are goal oriented). Therefore, people will pay attention only to those stimuli that are easy to process and strongly associated with the greatest avoidance of pain or the greatest production of pleasure.

There are two substantive implications of this model. First, if attention is a necessary condition for learning, then learning about political responsibilities is only possible in those issues or policy areas whose saliency increases over time. All-else-being-equal, as the saliency of policies varies over time, the attention that people pay to policies should also change. Our assumption is that the saliency of an issue is determined by the changing economic, political or social circumstances and therefore, it is exogenous to individuals and the mass media. Second, there are no reasons to expect that all individuals will pay the same amount of attention to a particular policy area. Similar to what Duch et al. (2000) argue when explaining perceptions of national economic conditions, individuals who derive greater benefits from having information about specific policy areas tend to have 
a better understanding about responsibility attribution between levels of government. In our paper, people out-of-work can be expected to pay a greater amount of attention to the decisions about unemployment. Not surprisingly, self-interested attitude -defined as one that is instrumental to the individual's attainment of valued goals, particularly those which bear directly on the material well-being of individuals' private lives (Sears et al., 1980: 671)- is a classical determinant of policy attitudes. Thus, following again Lupia and McCubbins (1998: chapter 2), it can be hypothesized that there is a positive interaction between self-interest indicators (i.e., the expected individual benefit from paying attention to an issue) and the saliency of the issue (i.e., the cost needed to process a stimulus into a useful inference).

However, as explained by Lau and Heldman (2009: 524), figuring out what one's selfinterest is on many political issues can be daunting even for the most politically sophisticated individuals. Therefore, self-interest effects might be limited to the most attentive members of the public: when an issue is salient, it is easier for individuals to make the link between their personal circumstances and the actions of politicians. The 'heterogeneous attribution' theory by Gomez and Wilson (2001) and the empirical evidence provided by Funk (2000) also go in this direction.

Our theoretical expectations specify that an individual's learning about responsibility attribution varies depending on the amount of attention they give to the political issue, and their social status or occupation. The hypotheses are as follows:

- When the saliency of an issue increases over time, the accuracy of individuals' attribution of responsibilities does so accordingly. We label this the saliency hypothesis. 
- As self-interested individuals seek out information that reflects their economic circumstances, economic self-interest will increase the accuracy of individuals' attribution of responsibilities. We label this the self-interest hypothesis.

- When the saliency of an issue increases, learning should be particularly important for those individuals who derive greater benefits from having information. We label this the interactive hypothesis.

\section{DATA AND METHODS}

Our analysis is based on individual data from Spain from two points in time: late 2007, the last year before the economic crisis, and late 2012. Two substantive and methodological reasons explain this decision. First, Spain is the country in the European Union (EU) that has suffered the most consequences of the current economic crisis in terms of employment levels. According to Eurostat ${ }^{\mathrm{ii}}$, Spain was the country showing the highest unemployment rate in 2012 in the EU-27 (25.0 per cent) and, more importantly for our purposes, the highest increase in the unemployment rate between 2007 (8.3 per cent) and 2012. This difference of 16.7 percentage points more than triples the average increase in unemployment rate (4.8 points) in the EU-27.

[Figure 1 about here]

Not surprisingly, this trend in the unemployment rate is clearly reflected in the different saliency of public issues in the pre-crisis and the current scenarios. Figure 1 shows the main problems in Spain according to respondents in monthly barometers by 
the Centro de Investigaciones Sociológicas (CIS) from 2007 to 2012. As can be seen, the share of respondents who thought that unemployment was the main problem of the country has doubled in 5 years, from 40 per cent to 80 per cent. The changes in the saliency of the issue of unemployment clearly respond to the evolution of the unemployment rate (see Figure 2). Leaving aside the catch-all category of 'economic problems', the saliency of all the remaining issues has clearly dropped from when they were relevant before the economic crisis (immigration and housing) or do not show significant changes when they were not (healthcare or education) ${ }^{\text {iii }}$.

[Figure 2 about here]

Second, the face-to-face survey interviews conducted by the Centro de Investigaciones Sociológicas before the economic crisis in 2007, and five years later, in 2012, are particularly well suited to examine the learning of responsibility attribution. The first study (CIS 2734) was conducted in October and November 2007 in five regions. A representative sample of 1,496 people were interviewed in Andalusia, 1,490 in Castile and Leon, 1,500 in Catalonia, 2400 in Galicia and 1,491 in the Basque Country. The second study (CIS 2956) was conducted between 13 September and 9 October, 2012 in the same regions: 1,430 people were interviewed in Andalusia, 965 in Castile and Leon, 1,190 in Catalonia, 585 in Galicia and 425 in the Basque Country. The samples are also representative. More interestingly, the questionnaires of both surveys include a similar question tapping respondents' attribution of responsibilities. In the 2007 survey, the question is as follows: 'Which is the most responsible level of government (central government, regional government or local government) for the administration of the following services?'. In 2012, the question is slightly different: 'Which is the most 
responsible level of government (central government, regional government or local government) if things go well or badly in the following policy areas?' The individuals from the five regions have been pooled, as our arguments about learning should travel across regions. Accordingly, the samples in both years have been weighted to bring regional sample proportions in line with national population proportions based on census data.

The dependent variable is the accuracy of individuals' attribution of responsibility on unemployment. If respondents correctly identify the most responsible level of government in the area (national level), the value of the dependent variable is 1 ; for both the incorrect attribution of responsibility and Don't Know/No Answer the value of the dependent variable is $0 .{ }^{\text {iv }}$ Given that the dependent variable is dichotomous, binomial logistic regression is run

Roughly speaking, self-interest can be measured with objective or exogenous indicators (i.e., objective measures that distinguish between those who stand to benefit and those who stand to lose for a given policy) and subjective or endogenous indicators (i.e., judgments about whether people would personally be harmed or benefitted by a public policy given their own account of what constitutes a cost or a benefit to them). Unfortunately, in the two questionnaires that we are using in the empirical analysis, there are no questions asking respondents to indicate whether the policy would have or has had either positive or negative consequences for themselves personally. Therefore, we have to use a crude proxy for self-interest based on the findings of previous research. In our study, self-interest on unemployment concerns whether or not the respondent was part of 
the working population, ${ }^{\mathrm{V}}$ as Sears et al. (1980: 673) and Lau and Heldman (2009: 517) do.

There are two key independent variables. First, in order to capture learning about the attribution of responsibility over time, we have created a dummy variable, 2012 year, that equals 1 for respondents in the 2012 survey and 0 for respondents in the 2007 survey. Given the enormous increase in the unemployment rate in Spain, we expect a very significant increase in the accuracy of responsibility attribution for this policy. Second, in order to test the self-interest hypothesis, we have included dummy variables that equal 1 for those individuals who belong to the group with a particular self-interest in unemployment, and 0 otherwise.

Relying on existing research (for instance, Hobolt and Tilley, 2014), we have included five individual-level control variables that capture perceptual biases and informational differences across individuals. Roughly speaking, it should not only be individuals with greater access to information but also, given the negative economic situation, opposition partisans who make more accurate attributions of responsibilities. The variables are the following:

- Male is a dummy variable that equals 1 for men and 0 for women. According to the previous literature, the variable should enter positively in the model as men tend to show higher levels of political knowledge than women (see Fraile 2014).

- We expect a positive relationship between age and political knowledge, although a decline in this relationship has been demonstrated in advanced ages in previous works (Lau and Redlawsk 2009). For this reason, Age (in years) and Age-squared 
(to capture a potential non-linear relationship) are included in the models. The expected signs are positive and negative, respectively,

- Education is a categorical variable that equals 1 for those individuals with no studies or primary studies, 2 for those respondents with secondary studies, and 3 for those individuals with university studies. As education is an important determinant of political knowledge, the variable should enter positively in the model.

- Political awareness is a dummy variable that equals 1 if the respondent knows the name of the corresponding regional Prime Minister, 0 otherwise. The expected sign is positive.

- Voting behaviour is a variable that distinguishes between government supporters (the reference category), opposition supporters and abstainers according to respondents' voting behaviour in the last national election. ${ }^{\text {vi }}$. Due to the lack of a variable measuring party identification in the questionnaires, voting behaviour is a proxy for partisanship. As shown by Tilley and Hobolt (2011), when government partisans have a negative view of the economic situation, they tend to think that the government is not responsible. Considering the adverse economic situation, opposition supporters should make more accurate responsibility attributions than government supporters, while the expectation is not clear in the case of abstainers.

- Finally, we also include a variable that controls for the region in which respondents live to capture institutional and economic differences ${ }^{\mathrm{vii}}$ (see León, 2010, 2012).

The descriptive statistics of the independent variables are shown in Table 1. 
[Table 1 about here]

The purpose of this paper is to analyse to what extent responsibility attribution changed between 2007 and 2012. Unfortunately, panel data observing the same set of individuals over several years is not available. Therefore, we employ two cross-section surveys in which the same questions about responsibility attribution are asked to different samples of individuals from the same population. A pooled cross-sectional analysis (Firebaugh, 1997) allows us to track trends in the accuracy of responsibility attribution between levels of government and to establish causal inferences. . We have pooled the 2007 and 2012 cross-sectional surveys. The dummy variable (2012 year), which identifies the respondents from each survey, captures whether there are differences in responsibility attribution over time controlling for the same variables in the two years. The interaction of the 2012 year with the independent variable of interest shows whether the impact of the latter is significantly different in the two moments in time. ${ }^{\text {viii }}$

Individuals might perceive that the role of the central government has strengthened as a consequence of the economic crisis, which would make our argument spurious. To counter this and to support our argument, two policies in the hands of the national government are considered in the empirical analysis; unemployment and immigration. If the crucial mechanism is the role of the national government, we should observe that the accuracy in responsibility attribution increases in both policies; but if the mechanism is simply the saliency of issues, it should only be in the case of unemployment that individuals have more information in 2012 than in 2007 about who is in charge. What we found is the latter and this clearly supports our argument. 


\section{RESULTS}

We start our discussion of the results by looking at the distribution of our dependent variable. The accuracy of responsibility attribution in unemployment (and on other three policies in which the interest has decreased $)^{\mathrm{ix}}$ is displayed in Table 2 . The only area in which the share of respondents correctly identifying the most responsible level of government has increased over time is unemployment (national level): accurate attributions are 14 points higher in 2012 than in 2007. On the contrary, in the other three policy areas, especially in healthcare and immigration, the attribution of responsibility is less accurate in 2012 than in 2007. The understanding of how responsibilities are allocated between levels of government is worse in these three areas in 2012 than it was five years earlier. In other words, the level of government with the primary responsibility (the same in both years) or the ideology of the incumbent (different at least at the national level in the two moments), do not explain differences over time among policy areas. These results strongly support the saliency hypothesis.

\section{[Table 2 about here]}

To explore the robustness of the initial findings and to test the saliency, selfinterest, and the interactive hypotheses, we include the two key independent variables and the controls in our logit regression models. We run two specifications: an additive model with the dummy variable identifying the observations corresponding to 2007 and 2012, the self-interest variable, and the control variables (model A); and an interactive model in which an interaction term -between 2012 year and self-interest- is added to the previous specification (model B). ${ }^{\mathrm{x}}$ 
The results when explaining the attribution of responsibility in unemployment are displayed in Table 3. First, the additive model (A) confirms that learning depends on the saliency of issue. As expected, we found evidence in favour of learning about responsibility attribution for unemployment: 2012 year is positive and statistically significant at the 0.01 level. This means that the accuracy of individuals' attribution of responsibility is higher in 2012 than in 2007. ${ }^{\mathrm{x}}$ The saliency hypothesis is clearly supported. The coefficient on Self-interest in the additive model is not statistically significant. This statistically insignificant impact of self-interest is clearly in line with previous research. For instance, "we found self-interest to have little effect on voters' policy preferences, while symbolic attitudes had major effects ... But only four of our thirteen self-interest indicators had even a statistically significant effect" (Sears et al., 1980: 773). Similarly, in the more recent paper by Lau and Heldman (2009: 515), they find that "on average across the four issue domains, the various self-interest indicators explained only $1 \%$ of the variance over that already explained by symbolic beliefs, while the symbolic beliefs collectively explained 10 times more of the explainable variance in policy attitudes above that already accounted for by self-interest".

On the other hand, the variables political awareness and voting for the opposition have the expected signs and are significant, increasing the accuracy of individuals' attribution of responsibility. The squared transformation of the variable age shows that the older citizens tend to make incorrect attributions of responsibility. Apart from the regional dummies, all of them are statistically significant in our models. However, gender, age, and education are not statistically significant . 
Second, when explaining the attribution of responsibility for unemployment, the individuals who were in the working population have learned more about which level of government makes the decisions in this area than the rest of the population. The interaction is statistically significant at the 0.01 level. ${ }^{\text {xii }}$ In other words, as expected in our interactive hypothesis, learning is higher for those who derive greater individual benefits from having information when the issue is salient.

[Table 3 about here]

Based on the results of the interactive model in Table 3, Figure 3 shows the marginal effect of the saliency of unemployment on the accuracy of responsibility attribution in this policy area. It is not only those individuals who derive greater benefits from being informed about unemployment (the working population) but also the rest of the population who have a better understanding of responsibility attribution in 2012 than in 2007. However, learning is more substantial for the former than for the latter.

[Figure 3 about here]

\section{CONCLUSIONS}

Learning is crucial for understanding the long-term impact of institutions. Given the global trend towards decentralization, it is essential to clarify whether learning about "who is responsible for what' can affect the well-known trade-off between efficiency and accountability in multilevel states. The ability of voters to correctly assign responsibility is conditio sine qua non for holding government accountable for action and outcomes and then to make them representative. 
As there are no reasons to expect that all individuals learn the same about the same things, we have argued in this paper that learning is driven by the attention that people pay to issues and their (economic) self-interests. This is what the models in social psychology and cognitive science state. The current economic crisis in Spain provides an ideal scenario for testing our argument about learning with observational data. The spectacular increase in the unemployment rate, from 8.3 percent in 2007 to 25.0 percent in 2012, has affected the saliency of issues between 2007 and 2012. Additionally, it is possible to identify a group with a self-interest: the working population tend to have a better understanding of how decisions are made in that area.

Using a pooled cross-sectional analysis with individual data, we find support for our argument. We have shown that individuals have a better understanding of responsibility in 2012 in unemployment than some years ago. This is clearly the consequence of the very different saliency of a policy area in two moments in time. Additionally, learning is particularly important for the working population. This means that self-interest constitutes a source of heterogeneity in the accuracy of responsibility attribution. The unintended consequence of the deep economic crisis is Spain has been an improvement in the ability of citizens to correctly assign responsibility to incumbents for managing the economy. In other words, the interaction between citizens and institutional arrangements are affected by exogenous shocks such as an economic crisis.

Of course, more investigation should be done to find out the consequences of economic crises on the attribution of political responsibilities. There are three avenues worth exploring for understanding the role of exogenous shocks. First, using panel data instead of repeated surveys is crucial for clarifying who learns and who does not. Second, 
(lab or survey) experiments are a fruitful avenue to explore how individuals learn to assign responsibilities. Third, it can be hypothesized that an individual's learning about responsibility attribution varies depending on the longevity of the democracy in the state where they live and the decentralization process together with the degree to which the power is shared between national and subnational incumbents.

NOTES:

\footnotetext{
${ }^{\mathrm{i}}$ According to the World Bank (2000: 107), at the beginning of the $21^{\text {st }}$ century 'some 95 percent of democracies $[\ldots]$ have elected subnational governments, and countries everywhere - large and small, rich and poor - are devolving political, fiscal, and administrative powers to subnational tiers of government'. ii http://epp.eurostat.ec.europa.eu/statistics_explained/index.php/Unemployment_statistics

iii Differences between 2007 and 2012 are only statistically significant for unemployment, economy, immigration and housing.

iv Our results do not change appreciably when the Don't Know and No Answer are dropped from the models.

v Those employed or actively seeking employment are the 'working population', while the 'passive population' includes retired, students, and housekeepers.

${ }^{v i}$ When there are coalition governments, supporters of any member of the coalition are considered as government supporters.

vii As is well known (León, 2010, 2012), Spain shows strong differences across regions in expenditure and tax powers. On the one hand, 'fast-track' Autonomous Communities (Andalusia, Catalonia, Galicia and the Basque Country in our sample) received (more) powers over some policy areas earlier than 'slow-track' ones (Castile and Leon in our sample). On the other hand, some Autonomous Communities enjoy a 'foral regime' (the Basque Country in our sample) and therefore major taxes are fully administered by the regional governments. However, these institutional differences are not relevant for explaining learning since the most responsible level of government in the four selected areas is the same both in 2007 and 2012 in the five Autonomous Communities and learning is not correlated with the time each Autonomous Community has held its powers. Interestingly, for unemployment, which is the only area in which the aggregate share of respondents correctly identifying the most responsible level of government has increased over time, the attribution of responsibility is more accurate in 2012 than in 2007 in all the five Autonomous Communities. Roughly speaking, differences in expenditure and tax powers are not correlated with differences over time in the accuracy of responsibility attribution in the five policy areas (see Table 4 in the appendix). Similarly, the economic situation differs across the five regions. According to the Spanish National Statistics Institute and Eurostat, GDP per capita and unemployment rates in 2012 were the following: Andalusia, 16,774 $€$ and 34.6 per cent; Castile and Leon, 22,000 $€$ and 19.8 per cent; Catalonia, 26,419 $€$ and 22.5 per cent; Galicia, $20,336 €$ and 20.5 per cent; and the Basque Country, 30,051 $€$ and 15.6 per cent.

viii The number of observations is not enough to perform a multilevel analysis. A multilevel analysis requires at least 20 groups and 30 observations per group (Heck and Scott, 2000). Alternative recommendations are 30 groups and 30 observations per group (Hox, 2002), 50 groups and 30 observations per group (Mass and Hox, 2004), or at least 20 micro observations per macro-level observation (Bickel, 2007).

ix These three additional areas have been selected for one reason: there is clearly a level of government with the primary responsibility -the central government for immigration (and unemployment) and the regional government for education and healthcare.

${ }^{x}$ The models for the attribution of responsibility in the three additional policies (education, healthcare and immigration) are shown in Table 5 (appendix). In these models, the "self-interested" populations are the following. For the healthcare issue, self-interest is defined in terms of age. According to a recent report (Calero and Izquierdo, 2013), public demand for spending in healthcare in Spain is mainly affected by age. Consequently, a dummy variable that equals 1 for people older than 65 years, and a value of 0 for younger correspondents has been created. According to the same report, the most important variable explaining the impact of public spending on education in Spain is the level of income of families. However, this variable is absent in the questionnaires we are using, with the variable 'being a student' as our crude proxy for selfinterest. Finally, for immigration, self-interest was indexed by having a temporary contract or being unemployed. As explained by Ceobanu and Escadell (2010: 319), because most immigrants in
} 
economically developed societies are non-specialists, natives from a lower socio-economic status or with a vulnerable status (e.g., the unemployed) face stern competition from immigrants.

${ }^{x i}$ However, for the other three policy areas -healthcare, education and immigration- 2012 year is negative and statistically significant at the 0.01 level. That is, the understanding of how responsibilities are allocated between levels of government is worse in 2012 than in 2007.

${ }_{\text {xii }}$ As shown in Table 5 (appendix), the remaining three interactions are not significant and in the case of education and immigration, the signs are even negative. 


\section{REFERENCES}

Anderson, C.A (2006) Economic voting and multilevel governance: A Comparative Individual-Level Analysis. American Journal of Political Science 50: 449-463.

Anderson, C.J (2000) Economic Voting and Political Context: A Comparative Perspective. Electoral Studies 19: 151-170.

Anderson, C. J (2007a) The End of Economic Voting? Contingency Dilemmas and the Limits of Democratic Accountability. Annual Review of Political Science 10: 271-296.

Anderson, C. J (2007b) Interaction of Structures and Voter Behavior in The Oxford Handbook of Political Behavior. Eds. R.J. Dalton and H.D. Klingemann. Oxford: Oxford University Press, pp. 589-609.

Bickel, R., (2007) Multilevel Analysis for Applied Research: It's Just Regression! New York, NY: Guilford Press.

Calero, J. and M. Gil Izquierdo (2013) La Incidencia Distributiva del gasto Público en Educación y Sanidad en España in Primer Informe de Desigualdad en España. Madrid: Fundación Alternativas, pp. 243-279.

Ceobanu, A. M. and X. Escandell (2010) Comparative Analyses of Public Attitudes Toward Immigrants and Immigration Using Multinational Survey Data: a Review of Theories and Research. Annual Review of Sociology 36: 309-328.

Cox, G.W (1997) Making Votes Count. Strategic Coordination in the World's Electoral Systems. New York: Cambridge University Press.

Cutler, F (2004) Government Responsibility and Electoral Accountability in Federations. Publius. The Journal of Federalism 34: 19-38.

Duch, R.M., H.D. Palmer and C.J. Anderson (2000) Heterogeneity in Perceptions of National Economic Conditions. American Journal of Political Science 44: 635-652. 
Duch, R. and R. Stevenson (2013. Voter Perceptions of Agenda Power and Attribution of Responsibility for Economic Performance. Electoral Studies 32: 512-516.

Duch, R., W. Przepiorka and R. Stevenson (2014) Responsibility Attribution for Collective Decision Makers. American Journal of Political Science, DOI: 10.1111/ajps.12140.Escobar-Lemmon, M. (2003) Political Support for Decentralization: An Analysis of the Colombian and Venezuelan Legislatures. American Journal of Political Science 47: 683-697.

Firebaugh, G. (1997) Analyzing repeated surveys. Sage University Paper Series on Quantitative Applications in the Social Sciences. Series/Number 07-115. Thousand Oaks: Sage.

Fraile, M. (2014) Do Women Know Less About Politics Than Men? The Gender Gap in Political Knowledge in Europe. Social Politics. Published online. Doi: 10.1093/sp/jxu006

Funk, C. L (2000) The Dual Influence of Self-Interest and Societal Interest in Public Opinion. Political Research Quarterly 53: 37-62.

Gomez, B.T. and J.M. Wilson (2001) Political Sophistication and Economic Voting in the American Electorate: A Theory of Heterogeneous Attribution. American Journal of Political Science 45: 899-914.

Heck, R.H. and T.L. Scott (2000) An Introduction to Multilevel Modelling Techniques. Mahwah, New Jersey: Laurence Erlbaum Associates.Herrero, A, M. Goenaga and J. Ruiz-Huerta (2015) Finanzas Autonómicas: Visibilidad, Transparencia y Atribución de Responsabilidades. Papeles de Economía Española 143: 185-204.

Hobolt, S.B. and J. Tilley (2014) Who's in Charge? How Voters Attribute Responsibility in the European Union. Comparative Political Studies 47: 795-819. 
Hobolt, S. B., J. Tilley and J. Wittrock (2014) Listening to the Government: How Information Shapes Responsibility Attributions. Political Behavior 35: 153-174.

Hox, J.J (2002) Multilevel Analysis: Techniques and Applications. Mahwah, New Jersey: Lawrence Erlbaum Associates.Lago, I. and S. Lago (2010) Decentralization and electoral accountability. Environment and Planning C: Government and Policy: 28: 18334.

Lago, S. and I. Lago (2013) La atribución de responsabilidades políticas en Estados descentralizados. Cuadernos Económicos de ICE 85:44-63.

Lau, R. R. and C. Heldman (2009) Self-Interest, Symbolic Attitudes, and Support for Public Policy: A Multilevel Analysis. Political Psychology 30: 513-537.

Lau, R.R. and D.P Redlawsk (2009) Older but Wiser? Effects of Age on Political Cognition. The Journal of Politics 70 (1): 168-185

León, S. (2010) Who is Responsible for What? Clarity of Responsibilities in Multilevel States: The Case of Spain. European Journal of Political Research 50: 80109.

León, S. (2012) How do Citizens Attribute Responsibility in Multilevel States? Learning, biases and asymmetric federalism. Evidence from Spain. Electoral Studies 31: 120-130. León, S. (Coord.) (2015) La Financiación Autonómica. Claves para Comprender un (Interminable) Debate. Madrid: Alianza.

León, S. and M. Ferrín (2007) La atribución de responsabilidades sobre las políticas públicas en un sistema de gobierno multinivel. Administración \& Ciudadanía 2: 49-75.

Linz, Juan (1989). Spanish Democracy and the Estado de los Autonomías, in Forging Unity Out of Diversity. Eds. R.A. Goldwin, A. Kaufman, and W.A. Schambra. Washington, DC: American Enterprise Institute; 1989. p. 260-326. 
López, J. and F. Rodrigo (2012) ¿Por qué los españoles son (moderadamente) autonomistas? Las ganancias regionales de eficiencia y la preferencia por la autonomía? Ekonomiaz 81: 63-81.

López, J. and F. Rodrigo (2014): Los ciudadanos ante las haciendas regionales: quién es y quién debería ser responsable de los servicios e impuestos autonómicos. Revista de Economía Aplicada 65: 1-28.

Lupia, A. and M.D. McCubbins (1998) The Democratic Dilemma. Can Citizens Learn What They Need To Know? New York: Cambridge University Press.

Mass, C.J.M. and J.J. Hox (2004) Robustness Issues in Multilevel Regression Analysis. Statistica Neerlandica 58: 127-13.

Powell, G. B. Jr. and G. Whitten (1993. A Cross-national Analysis of Economic Voting: Taking Account of the Political Context. American Journal of Political Science 37: 391-41.

Rudolph, T.J (2003a) Institutional Context and the Assignment of Political Responsibility. Journal of Politics 65: 190-215.

Rudolph, T. J (2003b) Who's Responsible for the Economy? The Formation and Consequences of Responsibility Attributions. American Journal of Political Science 47: 698- 713.

Sears, D. O., R. R. Lau, T. R. Tyler and H. M. Allen (1980) Self-Interest vs. Symbolic Politics in Policy Attitudes and Presidential Voting. American Political Science Review 74: 670-684.

Tavits, M. and T. Annus (2006) Learning to Make Votes Count: The Role of Democratic Experience. Electoral Studies 25: 72-90. 
Tilley, J. and S.B. Hobolt (2011) Is the government to blame? An Experimental Test of How Partisanship Shapes Perceptions of Performance and Responsibility. The Journal of Politics 73: 1-15.

Weingast, Barry R. (1995) "The Economic Role of Political Institutions: Marketpreserving federalism and Economic Development". Journal of Law, Economics and Organizations 11: 1-31.World Bank (2000) The World Development Report 1999/2000. Entering the $21^{\text {st }}$ Century. Washington, D.C.: The World Bank and Oxford: Oxford University Press. 
TABLES

Table 1. Descriptive statistics-independent variables

\begin{tabular}{|c|c|c|c|c|c|}
\hline Variable & Observations & Mean & Std. Dev & Min. & Max. \\
\hline 2012 year & 12964 & 0.34 & 0.48 & 0 & 1 \\
\hline Male & 12964 & 0.48 & 0.50 & 0 & 1 \\
\hline Age & 12955 & 47.39 & 18.24 & 18 & 98 \\
\hline \multicolumn{6}{|l|}{ Education } \\
\hline Primary or less & 12916 & 0.31 & 0.46 & 0 & 1 \\
\hline Secondary & 12916 & 0.49 & 0.50 & 0 & 1 \\
\hline University & 12916 & 0.19 & 0.39 & 0 & 1 \\
\hline Political awareness & 11546 & 0.91 & 0.28 & 0 & 1 \\
\hline \multicolumn{6}{|l|}{ Voting behaviour } \\
\hline Government & 12961 & 0.29 & 0.45 & 0 & 1 \\
\hline Opposition & 12961 & 0.32 & 0.46 & 0 & 1 \\
\hline Abstention & 12961 & 0.39 & 0.49 & 0 & 1 \\
\hline Working population (self-interest) & 12964 & 0.60 & 0.49 & 0 & 1 \\
\hline
\end{tabular}

Source: Studies 2734 and 2956 of the Centro de Investigaciones Sociologicas (CIS). 
Table 2. Accuracy of responsibility attribution: descriptive statistics*

\begin{tabular}{l|ccc}
\hline & 2007 & 2012 & Difference \\
\hline Unemployment & 51 & 65 & +14 \\
Healthcare & $(4288)$ & $(2971)$ & \\
& 57 & 50 & -7 \\
Education & $(4795)$ & $(2287)$ & -4 \\
Immigration & 51 & 47 & -8 \\
& $(4252)$ & $(2136)$ & \\
\hline
\end{tabular}

*In each cell, the share of respondents correctly attributing the responsibility and, in parentheses, the number of respondents.

Source: Studies 2734 and 2956 of the Centro de Investigaciones Sociológicas (CIS). 
Table 3. Accuracy of responsibility and attribution on unemployment: regression models

\begin{tabular}{|c|c|c|c|c|}
\hline & \\
\hline & \multicolumn{2}{|l|}{ A } & \multicolumn{2}{|c|}{$\mathrm{B}$} \\
\hline \multicolumn{5}{|l|}{ Region (ref: Basque Country) } \\
\hline \multirow[t]{2}{*}{ Andalusia } & 0.26 & $* *$ & 0.26 & $* *$ \\
\hline & $(0.07)$ & & $(0.07)$ & \\
\hline \multirow[t]{2}{*}{ Castile and Leon } & 0.92 & $* *$ & 0.91 & $* *$ \\
\hline & $(0.08)$ & & $(0.08)$ & \\
\hline \multirow[t]{2}{*}{ Catalonia } & 0.68 & $* *$ & 0.68 & $* *$ \\
\hline & $(0.07)$ & & $(0.07)$ & \\
\hline \multirow[t]{2}{*}{ Galicia } & 0.76 & $* *$ & 0.76 & $* *$ \\
\hline & $(0.07)$ & & $(0.07)$ & \\
\hline \multirow[t]{2}{*}{ Man } & 0.02 & & 0.02 & \\
\hline & $(0.05)$ & & $(0.05)$ & \\
\hline \multirow[t]{2}{*}{ Age } & 0.01 & & 0.01 & \\
\hline & $(0.01)$ & & $(0.01)$ & \\
\hline \multirow[t]{2}{*}{ Age (square) } & -0.00 & $*$ & -0.00 & $*$ \\
\hline & $(0.00)$ & & $(0.00)$ & \\
\hline \multicolumn{5}{|l|}{ Education level (ref: primary) } \\
\hline \multirow[t]{2}{*}{ Secondary } & 0.09 & & 0.08 & \\
\hline & $(0.07)$ & & $(0.07)$ & \\
\hline \multirow[t]{2}{*}{ University } & 0.04 & & 0.04 & \\
\hline & $(0.08)$ & & $(0.08)$ & \\
\hline \multirow[t]{2}{*}{ Political awareness } & 0.23 & $*$ & 0.22 & $* *$ \\
\hline & $(0.08)$ & & $(0.08)$ & \\
\hline \multicolumn{5}{|l|}{ Voting behaviour (ref. Government) } \\
\hline \multirow[t]{2}{*}{ Opposition } & 0.21 & $* *$ & 0.21 & $* *$ \\
\hline & $(0.06)$ & & $(0.06)$ & \\
\hline \multirow[t]{2}{*}{ Abstention } & 0.05 & & 0.04 & \\
\hline & $(0.06)$ & & $(0.06)$ & \\
\hline \multirow[t]{2}{*}{2012 Wave } & 0.57 & $* *$ & 0.40 & $* *$ \\
\hline & $(0.05)$ & & $(0.07)$ & \\
\hline \multirow[t]{2}{*}{ Self-interest } & 0.06 & & -0.04 & \\
\hline & $(0.06)$ & & $(0.07)$ & \\
\hline \multirow[t]{2}{*}{ Self-interest*2012 } & & & 0.27 & $* *$ \\
\hline & & & $(0.09)$ & \\
\hline \multicolumn{5}{|l|}{ Cuts ordinal logit } \\
\hline \multicolumn{5}{|l|}{$\mu 1$} \\
\hline \multicolumn{5}{|l|}{$\mu 2$} \\
\hline$\mu 3$ & & & & \\
\hline Constant & -1.02 & $* *$ & -0.93 & $* *$ \\
\hline & $(0.21)$ & & $(0.22)$ & \\
\hline $\mathrm{N}$ & 11,361 & & 11 , & \\
\hline Pseudo R-Square & 0.03 & & & \\
\hline
\end{tabular}

Note: Robust standard errors in parentheses.

$* \mathrm{p} \leq 0.05$. ** $\mathrm{p} \leq 0.01$.

Source: Studies 2734 and 2956 of the Centro de Investigaciones

Sociológicas (CIS). 


\section{FIGURES}

Figure 1: Main problems for respondents in monthly barometers in Spain, 2007-2012

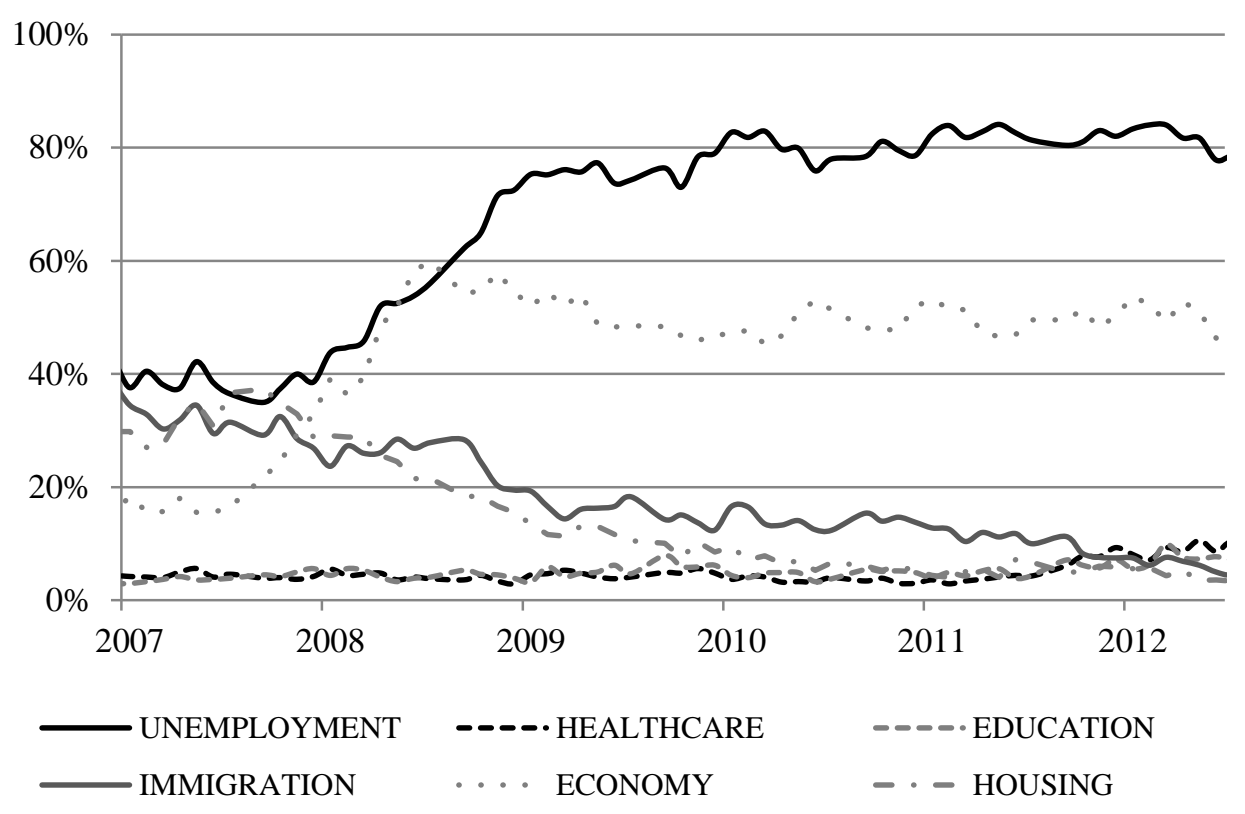

Source: Barometers of the Centro de Investigaciones Sociológicas (CIS). 
Figure 2:

Saliency of unemployment in monthly barometers and unemployment rate in Spain, 2008-2012

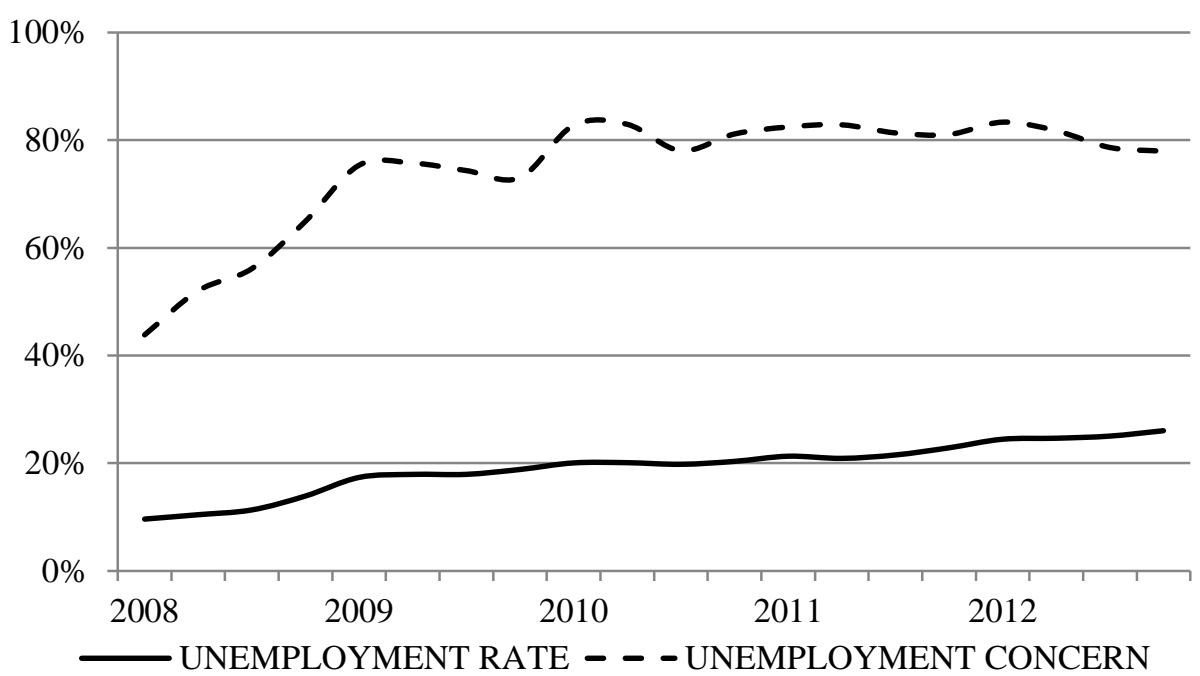

Source: Centro de Investigaciones Sociológicas (CIS) and Instituto Nacional de Estadística (INE). 
Figure 3: Marginal effect of the saliency of the unemployment issue on the accuracy of responsibility attribution

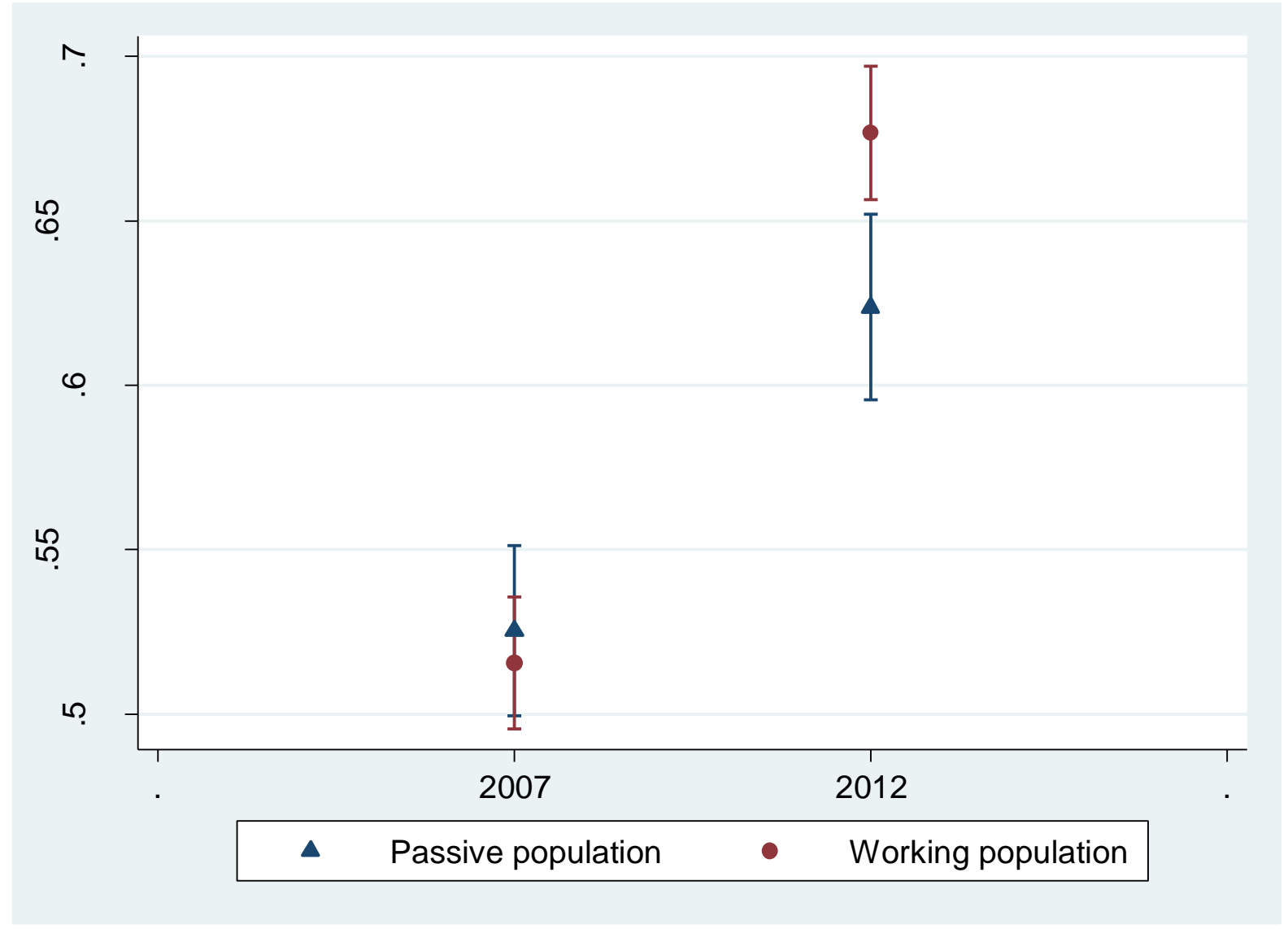

Source: Studies 2734 and 2956 of the Centro de Investigaciones Sociológicas (CIS).

Bars represent 95 per cent confidence intervals. 


\section{APPENDIX}

Table 4. Difference (in points) in the accuracy of responsibility attribution by Autonomous Communities (2012-2007)

\begin{tabular}{|l|c|c|c|c|c|}
\hline & \multicolumn{5}{|c|}{ Autonomous Community } \\
\hline & Andalusia & Castile and Leon & Catalonia & Galicia & Basque Country \\
\hline Unemployment & +8 & +14 & +28 & +3 & +7 \\
\hline Healthcare & -8 & +2 & -8 & +9 & -3 \\
\hline Education & -17 & -10 & +2 & -4 & -2 \\
\hline Immigration & -13 & +2 & -1 & -22 & -1 \\
\hline
\end{tabular}

Source: Studies 2734 and 2956 of the Centro de Investigaciones Sociológicas (CIS). 
Table 5. Accuracy of responsibility and attribution on three additional policies: regression models

\begin{tabular}{|c|c|c|c|c|c|c|c|c|c|c|c|c|}
\hline & & & & & & & & & & & & \\
\hline & \multicolumn{4}{|c|}{ HEALTHCARE } & \multicolumn{4}{|c|}{ EDUCATION } & \multicolumn{4}{|c|}{ IMMIGRATION } \\
\hline & \multicolumn{2}{|c|}{ A } & \multicolumn{2}{|l|}{$\mathrm{B}$} & \multicolumn{2}{|c|}{$\mathrm{A}$} & \multicolumn{2}{|l|}{$\mathrm{B}$} & \multicolumn{2}{|c|}{ A } & \multicolumn{2}{|l|}{$\mathrm{B}$} \\
\hline \multicolumn{13}{|c|}{ Region (ref: Basque Country) } \\
\hline \multirow[t]{2}{*}{ Andalusia } & -1.18 & $* *$ & -1.18 & $* *$ & -0.87 & $* *$ & -0.87 & $* *$ & 0.58 & $* *$ & 0.58 & $* *$ \\
\hline & $(0.08)$ & & $(0.08)$ & & $(0.07)$ & & $(0.07)$ & & $(0.07)$ & & $(0.07)$ & \\
\hline \multirow[t]{2}{*}{ Castile and Leon } & -0.82 & $* *$ & -0.82 & $* *$ & -0.72 & $* *$ & -0.72 & $* *$ & 1.19 & $* *$ & 1.19 & $* *$ \\
\hline & $(0.08)$ & & $(0.08)$ & & $(0.08)$ & & $(0.08)$ & & $(0.09)$ & & $(0.09)$ & \\
\hline \multirow[t]{2}{*}{ Catalonia } & -1.04 & $* *$ & -1.04 & $* *$ & -0.52 & $* *$ & -0.52 & $* *$ & 1.06 & $* *$ & 1.06 & $* *$ \\
\hline & $(0.08)$ & & $(0.08)$ & & $(0.07)$ & & $(0.07)$ & & $(0.089)$ & & $(0.08)$ & \\
\hline \multirow[t]{2}{*}{ Galicia } & -1.16 & $* *$ & -1.16 & $* *$ & -0.77 & $* *$ & -0.77 & $* *$ & 0.97 & $* *$ & 0.97 & $* *$ \\
\hline & $(0.08)$ & & $(0.08)$ & & $(0.07)$ & & $(0.07)$ & & $(0.08)$ & & $(0.08)$ & \\
\hline \multirow[t]{2}{*}{ Man } & 0.18 & $* *$ & 0.18 & $* *$ & 0.11 & $*$ & 0.11 & $*$ & 0.20 & $* *$ & 0.19 & $* *$ \\
\hline & $(0.05)$ & & $(0.05)$ & & $(0.04)$ & & $(0.04)$ & & $(0.05)$ & & $(0.05)$ & \\
\hline \multirow[t]{2}{*}{ Age } & 0.04 & $* *$ & 0.04 & $* *$ & 0.04 & $* *$ & 0.04 & $* *$ & 0.03 & $* *$ & 0.03 & $* *$ \\
\hline & $(0.01)$ & & $(0.01)$ & & $(0.01)$ & & $(0.01)$ & & $(0.01)$ & & $(0.01)$ & \\
\hline \multirow[t]{2}{*}{ Age (square) } & -0.00 & $* *$ & -0.00 & $* *$ & -0.00 & $* *$ & -0.00 & $* *$ & -0.00 & $* *$ & -0.00 & $* *$ \\
\hline & $(0.00)$ & & $(0.00)$ & & $(0.00)$ & & $(0.00)$ & & $(0.00)$ & & $(0.00)$ & \\
\hline \multicolumn{13}{|c|}{ Education level (ref: primary) } \\
\hline \multirow[t]{2}{*}{ Secondary } & 0.36 & $* *$ & 0.36 & $* *$ & 0.32 & $* *$ & 0.32 & $* *$ & 0.29 & $* *$ & 0.29 & $* *$ \\
\hline & $(0.06)$ & & $(0.06)$ & & $(0.06)$ & & $(0.06)$ & & $(0.07)$ & & $(0.07)$ & \\
\hline \multirow[t]{2}{*}{ University } & 0.86 & $* *$ & 0.86 & $* *$ & 0.71 & $* *$ & 0.71 & $* *$ & 0.53 & $* *$ & 0.53 & $* *$ \\
\hline & $(0.08)$ & & $(0.08)$ & & $(0.08)$ & & $(0.08)$ & & $(0.09)$ & & $(0.09)$ & \\
\hline \multirow[t]{2}{*}{ Political awareness } & 0.79 & $* *$ & 0.79 & $* *$ & 0.58 & $* *$ & 0.58 & $* *$ & 0.38 & $* *$ & 0.38 & $* *$ \\
\hline & $(0.08)$ & & $(0.08)$ & & $(0.08)$ & & $(0.08)$ & & $(0.08)$ & & $(0.08)$ & \\
\hline \multicolumn{13}{|c|}{ Voting behaviour (ref. Government) } \\
\hline \multirow[t]{2}{*}{ Opposition } & 0.06 & & 0.06 & & 0.16 & $* *$ & 0.16 & $* *$ & 0.24 & $* *$ & 0.24 & $* *$ \\
\hline & $(0.06)$ & & $(0.06)$ & & $(0.06)$ & & $(0.06)$ & & $(0.07)$ & & $(0.07)$ & \\
\hline Abstention & -0.18 & $* *$ & -0.18 & $* *$ & -0.06 & & -0.06 & & -0.04 & & -0.04 & \\
\hline & $(0.06)$ & & $(0.06)$ & & $(0.06)$ & & $(0.06)$ & & $(0.07)$ & & $(0.07)$ & \\
\hline 2012 Wave & -0.32 & $* *$ & -0.34 & $* *$ & -0.18 & $* *$ & -0.16 & $* *$ & -0.43 & $* *$ & -0.38 & $* *$ \\
\hline & $(0.05)$ & & $(0.05)$ & & $(0.04)$ & & $(0.05)$ & & $(0.05)$ & & $(0.07)$ & \\
\hline Self-interest & 0.00 & & -0.04 & & 0.04 & & 0.20 & & 0.05 & & 0.10 & \\
\hline & $(0.11)$ & & $(0.12)$ & & $(0.12)$ & & $(0.14)$ & & $(0.06)$ & & $(0.08)$ & \\
\hline Self-interest*2012 & & & 0.08 & & & & -0.44 & & & & -0.13 & \\
\hline & & & (0.11) & & & & $(0.22)$ & & & & (0.10) & \\
\hline
\end{tabular}

Cuts ordinal logit

$\mu 1$

$\mu 2$

$\mu 3$

\begin{tabular}{rcccccccccccc} 
Constant & & -0.93 & $* *$ & -0.93 & $* *$ & -1.03 & $* *$ & -1.03 & $* *$ & -1.02 & $* *$ & -1.07 \\
& & $(0.23)$ & $(0.23)$ & $(0.23)$ & $(0.23)$ & $(0.23)$ & $(0.24)$ \\
\hline $\mathrm{N}$ & 11,361 & 11,535 & 11,535 & 11,535 & 11,412 & 11,412 \\
& Pseudo R-Square & 0.06 & 0.06 & 0.04 & 0.04 & 0.05 & 0.05 \\
\hline
\end{tabular}

Note: Robust standard errors in parentheses.

$* \mathrm{p} \leq 0.05$. ** $\mathrm{p} \leq 0.01$.

Source: Studies 2734 and 2956 of the Centro de Investigaciones Sociológicas (CIS). 